\title{
EXERCÍCIO DE PERCEPÇÃO JURÍDICA DO ANTEPROJETO DO CÓDIGO BRASILEIRO DE PROCESSOS COLETIVOS ATRAVÉS DA TEORIA TRIDIMENSIONAL DO DIREITO
}

\section{EXERCISE OF JURIDICAL PERCEPTION OF THE PRE-PROJECT OF THE BRAZILIAN CODE OF COLLECTIVE PROCESSES}

\author{
Octaviano Langer" \\ Cesar Luiz Pasold"
}

\begin{abstract}
Resumo: $O$ presente artigo relata os resultados da utilização da Teoria Tridimensional do Direito, idealizada por Miguel Reale, como ferramenta de Percepção Jurídica aplicada ao Anteprojeto do Código Brasileiro de Processos Coletivos. Aplicando a ferramenta quanto ao fato, observou-se a evolução da Tutela Coletiva no Brasil, pontuando-se a necessidade de um Código Brasileiro de Processos Coletivos. No que diz respeito aos valores, destacam-se a mudança de paradigmas para a busca por soluções transindividuais para os conflitos jurídicos, e a tutela coletiva vista como um instrumento de acesso à justiça. Por fim, quanto à norma, examinou-se objetivamente o Anteprojeto do Código Brasileiro de Processos Coletivos, descrevendo-o e demonstrando sua importância para a alteração do ordenamento jurídico brasileiro, em especial no tocante aos processos destinados à tutela de direitos transindividuais.
\end{abstract}

Palavras-chave: Teoria. Fato. Valor. Norma. Código. Processo Coletivo.

Abstract: The present article reports the results of the use of the ThreeDimensional Theory of Law, idealized by Miguel Reale, as a tool of Juridical Perception applied to the Pre-project of the Brazilian Code of Collective Processes. By applying the tool on the fact, the study observed the evolution of the Collective Protection in Brazil, and highlighted the need for a Brazilian Code of Collective Processes. As far as values are concerned, this paper emphasizes the change of paradigms for the search

"Aluno Especial do Curso de Mestrado em Ciência Jurídica da Universidade do Vale do Itajaí - UNIVALI; Discente da disciplina Fundamentos da Percepção Jurídica, ministrada no semestre 2008.II. Email: amello@univali.br.

"Doutor em Direito do Estado pela Faculdade de Direito do Largo São Francisco, da Universidade de São Paulo/USP; Pós-Doutor em Direito das Relações Sociais pela Universidade Federal do Paraná/UFPR; Advogado - OAB/SC 943, Diretor Presidente do Advocacia Pasold e Associados - OAB/SC 059/90; Professor das Disciplinas "Metodologia da Pesquisa Jurídica", "Teoria do Direito Portuário", e "Fundamentos da Percepção Jurídica" no Curso de Mestrado em Ciência Jurídica da Universidade do Vale do Itajaí - UNIVALI. Consultor Científico da UNOESC. Consultor ad hoc da CAPES. Autor, entre outros, do livro Ensaio sobre a Ética de Norberto Bobbio. Florianópolis: Conceito Editorial, 2008. Co-autor, entre outras, da obra Novos Direitos- Conquistas e Desafios. Curitiba: Juruá, 2008. Email: amello@univali.br 
for transindividual solutions for juridical conflicts, and the view of collective protection as an instrument of access to justice. Finally, as for the norm, the Pre-project of the Brazilian Code of Collective Processes was objectively explained and described. At the same time, its importance for changes in the legal Brazilian management was demonstrated, specially regarding the processes aimed at the protection of transindividual rights.

Key-words: Theory. Fact. Value. Norm. Code. Collective Process.

\section{INTRODUÇÃO}

Neste artigo, a Teoria Tridimensional do Direito, idealizada por Miguel Reale, é utilizada como base teórica para compor um instrumento de Percepção Jurídica aplicável ao Anteprojeto do Código Brasileiro de Processos Coletivos.

A partir da teoria de Miguel Reale, pretende-se caracterizar os elementos fáticos, axiológicos e normativos que possam ter influenciado na elaboração do Anteprojeto do Código Brasileiro de Processos Coletivos na versão à data do presente artigo $^{1}$, percebendo a interação desta tríade (fato-valor-norma) com outras duas importantes variáveis (cronologia e poder) na composição do Anteprojeto.

O conceito operacional adotado para "Percepção Jurídica” é: a "ferramenta com a qual se examina, sob aporte(s) doutrinário(s) eleito(s), norma jurídica (legal; consuetudinária; jurisdicional; negocial), descrevendo-a e emitindo juízos valorativos a respeito dela"2.

Utilizou-se o método indutivo na fase de investigação, o método cartesiano na fase de tratamento dos dados recolhidos, e os resultados são apresentados sob o método indutivo, sendo operadas as técnicas do referente, da categoria, do conceito operacional e da pesquisa bibliográfica (PASOLD, 2008, p. 25-74, 81-105.

\section{CONSIDERAÇÕES GERAIS ACERCA DA TEORIA TRIDIMENSIONAL DO DIREITO}

A Teoria Tridimensional do Direito, idealizada por Miguel Reale, propõe

${ }^{1} 07$ de janeiro de 2009, quando o Anteprojeto foi acessado em http://www.direitoprocessual. org.br/dados/File/enciclopedia/CBPC\%202007\%2001\%2031\%20-020Entregue\%20 ao\%20governo.doc a partir do site http://www. direitoprocessual.org.br.

${ }^{2}$ Conceito operacional de Percepção Jurídica assim proposto pelo Prof. Doutor Cesar Luiz PASOLD no documento intitulado Plano de Ensino, da Disciplina Fundamentos da Percepção Jurídica - semestre 2008-I, datado de 15 de agosto de 2008. A tipologia indicada nos parênteses acima é proposta por REALE, Miguel. Fontes e Modelos do Direito - para um novo paradigma hermenêutico. São Paulo: Saraiva, 1994, em especial na p. 17. 
que o Direito não seja apenas norma, como também não seja apenas valor, nem tampouco apenas fato. O Direito, para Reale, é uma "integração normativa de fatos, segundo valores", sendo que "toda a norma jurídica assinala uma tomada de posição perante os fatos em função tensional de valores”, resultando que o Direito "só se constitui quando determinadas valorações dos fatos sociais culminam numa integração de natureza normativa" (REALE, 1994, 96-7, 103, grifo do autor).

Para Reale, a experiência jurídica pode ser compreendida através da implicação polar fato-valor, que resulta em um processo normativo integrante.

Nas palavras deste autor:

cada norma ou conjunto de normas representando, em dado momento histórico e em função de dadas circunstâncias, a compreensão operacional compatível com a incidência de certos valores sobre os fatos múltiplos que condicionam a formação dos modelos jurídicos e a sua aplicação (REALE, 1994, p. 74, grifo do autor).

Tais elementos se correlacionam numa relação dialética denominada por Reale (1994) de "dialética da complementariedade", sendo que

a compreensão do direito como "fato histórico-cultural" implica o conhecimento de que estamos perante uma realidade essencialmente dialética, isto é, que não é concebível senão como processus, cujos elementos ou momentos constitutivos são fato, valor e norma, a que dou o nome de "dimensão" em sentido, evidentemente, filosófico, e não físico-matemático. (p. 75, grifo do autor).

Ademais, as manifestações jurídicas, percebidas sob as três dimensões fato, valor e norma, interagem com duas outras importantes variáveis: tempo e poder.

A elaboração de uma norma jurídica é um processo em que se insere positivamente o poder, "quer o poder individualizado em um órgão do Estado, que o poder anônimo difuso no corpo social” (REALE, 1994, p. 61). E tais normas podem sofrer alterações semânticas, "pela superveniência de mudanças no plano dos fatos e valores” (REALE, 1994, p. 101) pelo transcorrer do tempo.

Por fim, na dialética das três dimensões, fato, valor e norma, a distinção vetorial destes elementos determinará três possibilidades epistemo-críticas: na Filosofia do Direito: compreensão axiológica de fatos em função de normas (fato $\rightarrow$ norma $\rightarrow$ valor); na Sociologia do Direito: compreensão factual de normas em função de valores (valor $\rightarrow$ norma $\rightarrow$ fato); na Ciência do Direito: compreensão normativa de fatos em função de valores (valor $\rightarrow$ fato $\rightarrow$ norma) (REALE, 1994, p. 151).

\section{APLICAÇÃO DA FERRAMENTA QUANTO AO FATO}

Para a análise fática dos aspectos destacados da tutela de direitos coletivos no Brasil, em especial a origem e os motivos da composição do Anteprojeto do Código Brasileiro de Processos Coletivos, deve-se inicialmente buscar em Miguel Reale o conceito de "fato". 
Para Reale (1994, p. 94-5, grifo do autor) o fato surge

desprovido de qualquer consistência estática e neutra. Põe-se, desde logo, como momento de um processo, um elo no encadeamento dos atos humanos, quer em função de atos anteriores, quer em razão de dados da natureza. [...] Envolve tanto aquilo que acontece, independentemente da iniciativa humana, mas adquire significado "inter homines" [...] como aquilo que intencionalmente é feito e se refere "ad alios". "Fato" é, por conseguinte, uma palavra que corresponde tanto ao particípio passado factum, de fieri (acontecer), com de facere (fazer).

Cabe então, para a definição do instrumento fático do Anteprojeto do Código Brasileiro de Processos Coletivos, caracterizar a evolução da tutela coletiva no Brasil, e a busca da identificação dos motivos que levaram a elaboração de um Anteprojeto de Código de Processos Coletivos no ordenamento pátrio.

\subsection{A Evolução da Tutela Coletiva no Brasil: Breve Relato}

Já na década de 60 o legislador brasileiro demonstrou preocupação com os direitos e interesses da coletividade, podendo-se indicar como um dos marcos iniciais da tutela coletiva no Brasil a regulamentação da Ação Popular em 1965 (através da Lei n. 4.717/65), instrumento jurídico que amparava os interesses da comunidade e que foi elevada a "status" de ação constitucional pela Constituição Brasileira de 1998.

Tal preocupação, destarte, manteve-se presente nas casas legislativas federais, tanto que em 1985 foi disciplinada a ação civil pública (Lei n. 7.347/85).

Ainda que tenha surgido "com o seu campo de aplicação restrito tanto quanto aos setores de sua incidência como em relação aos interesses que podiam ser defendidos mediante a utilização do novo instrumento processual" (MEIRELLES, 2003, p. 162), alterações legislativas posteriores acabaram por tornar a ação civil pública o principal meio para a tutela dos direitos oriundos das transformações sociais de então, também chamados "novos direitos" e que foram posteriormente nominados pelo Código de Defesa do Consumidor (Lei n. 8.078/90) como direitos difusos, coletivos e individuais homogêneos.

A Constituição Brasileira de 1988, contudo, tem sido o grande marco para a tutela dos direitos e interesses coletivos latu sensu. Ao assegurar inúmeros direitos e garantias individuais e coletivas, bem como uma série de direitos sociais, o legislador constituinte atribuiu à tutela coletiva importância destacada.

A defesa dos direitos do consumidor, do meio ambiente, dentre outros exemplos, será tanto mais eficaz, quando mais coletivamente forem tratados e defendidos. A ampliação dos poderes do Ministério Público, e as inúmeras garantias concedidas aos seus membros para a defesa da Sociedade, com destaque para o zelo dos direitos difusos e coletivos, também demonstra a mudança de enfoque do constituinte para a importância da tutela coletiva. 
Observa-se, pois, que a legislação tratando da tutela coletiva no Brasil não é recente. Ainda que a Lei da Ação Civil Pública (LACP) tenha sofrido algumas reformas há pouco tempo,como as Leis 9.494/97 e 10.741/97, que alteraram alguns artigos da LACP, grande parte dos dispositivos legais relacionados à tutela coletiva já completaram 20 anos ou mais de vigência.

Mazzili (2005, p. 58) constata:

Interesses difusos, coletivos e individuais homogêneos sempre existiram; não são novidade de algumas poucas décadas. Nos últimos anos, apenas se acentuou a preocupação doutrinária e legislativa em identifica-los e protegêlos jurisdicionalmente, agora sob o processo coletivo. A razão consiste em que a defesa judicial de interesses transindividuais de origem comum tem peculiaridades: não sé esses interesses são intrinsicamente transindividuais, como também sua defesa judicial deve ser coletiva, seja em benefício dos lesados, seja ainda em proveito da ordem jurídica.

E conclui:

Dessa forma, o legislador estipulou regras próprias sobre a matéria, especialmente para solucionar problemas atinentes à economia processual, à legitimação ativa, à destinação do produto da indenização e aos efeitos de imutabilidade da coisa julgada.

O que se percebe, contudo, é a dificuldade de instrumentalização e efetivação desses novos direitos.

A legislação processual civil atual, ainda de cunho individualista, temse mostrado ineficiente para a solução dos conflitos metaindividuais. Tanto na tutela de direitos difusos e coletivos, como na busca de soluções para os conflitos individuais homogêneos, faltam princípios e institutos próprios de um processo coletivo.

\subsection{A Tutela Coletiva hoje: necessidade de um Código Brasileiro de Processos Coletivos}

As dificuldades oriundas da falta de um ordenamento próprio para a instrumentalização da tutela coletiva já foram observadas por inúmeros juristas. Tanto teóricos como militantes forenses reconhecem a dificuldade de se utilizar a legislação processual civil brasileira, de matriz individualista, para a solução de conflitos transindividuais.

Paulo de Tarso Brandão, defensor da instrumentalização de Ações Constitucionais, já em 2001 escrevia acerca da incompatibilidade do Direito Processual Civil Brasileiro com a tutela dos chamados "novos direitos".

Nas palavras de Brandão (2001, p. 11)

defende-se a posição conforme a qual as ações constitucionais não podem ser entendidas a partir dos esquemas conceituais do Direito Processual Civil, uma 
vez que este tem o perfil e a finalidade de defesa de interesses interindividuais. Assim, os instrumentos consagrados na Constituição para a defesa destes "outros" direitos necessitam urgentemente de uma teoria geral própria.

\section{Pontua:}

É preciso, por exemplo, determinar qual a natureza do exercício do direito de ação e, por conseqüência, a natureza da legitimidade, da titularidade do objeto, da forma e das conseqüências do pedido, dos limites objetivos e subjetivos da coisa julgada e da execução.

Hugo Nigro Mazzili (2005, p. 48) igualmente comenta a necessidade de um instrumental próprio para a solução eficiente de demandas coletivas:

[...] sob o aspecto processual, o que caracteriza os interesses transindividuais, ou de grupo, não é apenas, porém, o fato de serem compartilhados por diversos titulares individuais reunidos pela mesma relação jurídica ou fática, mas, mais do que isso, é a circunstância de que a ordem jurídica reconhece a necessidade de que o acesso individual dos lesados à Justiça seja substituído por um processo coletivo, que não apenas deve ser apto para evitar decisões contraditórias como ainda deve conduzir a uma solução mais eficiente da lide, porque o processo coletivo é exercido de uma só vez em proveito de todo o grupo lesado.

A exposição de motivos do Anteprojeto do Código Brasileiro de Processos Coletivos também demonstra a carência de uma legislação própria para os processos coletivos, com princípios e institutos diversos do Direito Processual Individual:

a evolução doutrinária brasileira a respeito dos processos coletivos autoriza a elaboração de um verdadeiro Direito Processual Coletivo, como um ramo do direito processual civil, que tem seus próprios princípios e institutos fundamentais, diversos dos do Direito Processual Individual.

E prossegue:

Os institutos da legitimação, competência, poderes e deveres do juiz e do Ministério Público, conexão, litispendência, liquidação e execução da sentença, coisa julgada, entre outros, têm feição própria nas ações coletivas que, por isso mesmo, se enquadram numa Teoria Geral dos Processos Coletivos. (GRINOVER, 2009, p. 2).

Retornando a Reale (1994, p. 95) que conceitua fato "como momento de um

${ }^{3}$ Os autores deste artigo não ignoram que a obra citada já está em sua segunda edição, mas optaram em mencionar aqui a primeira edição pelo seu valor histórico e para homenagear Paulo de Tarso Brandão pelo pioneirismo de suas posições. $\mathrm{Na}$ segunda edição, publicada pela OAB/SC Editora, em 2006, Brandão prossegue com o mesmo posicionamento, inclusive quanto à forte defesa da tese de que "as Ações Constitucionais pertencem ao âmbito da Teoria Política e não do Processo Civil." (BRANDÃO, 2006, p. 23). 
processo, um elo no encadeamento dos atos humanos”, pode-se afirmar , então, que o Brasil se encontra num momento de carência de uma legislação específica para a tutela coletiva de direitos.

Ademais, e ainda invocando Reale (1994, p. 95), "todo fato, juridicamente relevante, já se acha imantado a um valor”.

Portanto, considerando a importância da tutela coletiva para a concretização de direitos, especialmente os constitucionalmente assegurados, percebe-se a importância de um Código Brasileiro de Processos Coletivos.

Conclui-se que a edição de um Código Brasileiro de Processos Coletivos, sob a ótica fática de Miguel Reale, é medida contemporânea e adequada para suprir a necessidade jurídica de um modo de disciplinamento do processo para a solução de demandas que envolvem os chamados "novos direitos", e possibilitar a garantia de direitos difusos e coletivos, garantidos em larga medida no texto constitucional brasileiro.

\section{APLICAÇÃO DA FERRAMENTA QUANTO AOS VALORES}

Para Miguel Reale (1994, p. 94, grifo do autor) a categoria "valor" indica "uma intencionalidade historicamente objetivada no processo da cultura, implicando sempre o sentido vetorial de uma ação possível”.

E também "valor é o elemento de mediação dialética entre fato e norma, sendo ele mesmo a expressão de um desenvolvimento histórico no plano das estimativas" (REALE, 1994, p. 153, grifo do autor).

Prosseguindo ainda amparados no pensamento de REALE (1994, p. 91, grifo do autor), deve-se entender

valor como um objeto autônomo, irredutível aos objetos ideais, como os lógicos e os matemáticos, ou seja, como entidades do mundo do "dever ser" e não do "ser"; e, posteriormente, pela compreensão da dialética de complementaridade que correlaciona fato, valor e norma.

A caracterização dos elementos axiológicos que envolvem a criação do Código Brasileiro de Processos Coletivos passa pela percepção dos valores que atualmente norteiam a atuação do judiciário brasileiro na solução de conflitos envolvendo a tutela coletiva, bem como daqueles (valores) que inspiram a criação de novos paradigmas para uma melhor implementação dos direitos difusos e coletivos neste país.

Assim, para se compreender o contexto axiológico que envolve a produção de um Código Brasileiro de Processos Coletivos, deve-se observar dois fenômenos que se correlacionam entre si: a busca por soluções transindividuais para os conflitos jurídicos, e a tutela coletiva como ferramenta de acesso à Justiça. 


\subsection{A busca por soluções transindividuais para os conflitos jurídicos}

É de se reconhecer hoje o aumento do número de ações coletivas. A tutela de direitos difusos, coletivos e individuais homogêneos ganha sempre mais corpo. Processos em defesa do meio ambiente, do consumidor, da moralidade pública chegam constantemente aos fóruns e tribunais. Em uma Sociedade complexa como a atual, "os processos coletivos são palco de conflitos internos da sociedade, relacionados, por vezes, com políticas públicas e com relevantes questões econômicas e, em certos casos com complexidade científica" (MENDES, 2007, p. 19).

Contudo, a evolução legislativa na área de processos coletivos não acompanhou a velocidade das transformações sociais, e percebe-se hoje a falta de instrumental jurídico adequado para responder eficientemente as demandas coletivas. Especialmente o Código de Processo Civil, de matriz eminentemente individualista, não só não oferece ferramentas eficientes para os conflitos de massa, como dificulta o ingresso e o processamento destes processos.

Questões como legitimidade 4 , competência, conexão, efeitos da sentença, dentre outras, atualmente reguladas pelo Código de Processo Civil e legislações esparsas, não coincidem com a realidade do processo coletivo.

Nas palavras de Mendes (2007, p. 16):

sob o ponto de vista formal, é de se notar que, com exceção da previsão genérica da possibilidade de uma legitimação extraordinária decorrente de lei expressa, contida no art. 6º , Código de Processo Civil não contém absolutamente nada em termos de normas voltadas para a tutela coletiva.

Como salienta Lenio Luiz Streck, percebe-se atualmente um distanciamento entre o Direito e a Sociedade. O Brasil passa por um momento de globalização e massificação das relações tanto sociais como jurídicas. Conflitos em série chegam ao Judicário, e acabam por atravancar o andamento dos processos nos fóruns, em grande parte pela falta de disciplinamento de soluções jurisdicionais coletivas.

Diz o referido autor:

preparado/engendrado para o enfrentamento dos conflitos transindividuais, o Direito e a dogmática jurídica (que o instrumentaliza) não consegue atender as especificidades das demandas originadas de uma sociedade complexa e

\footnotetext{
${ }^{4}$ Aliás, a categoria "legitimidade" é polissêmica e quando empregada em linguagem processualista pode provocar dúvidas, especialmente a partir de um sentido que se consolida na linguagem da Teoria do Estado. Vide, por exemplo, a condição de legitimidade do Poder em Pasold (2003, p. 71). Vide também os ensaios “ Legitimidade: conceito, fundamentos e medidas" e "Sobre a Legitimidade do Direito" em Pasold (1988, p. 20-24, 25-31). Vide ,também, o conceito para Legitimidade de autoria de Bobbio (2003, p. 82).
} 
conflituosa (J. E. Faria). O paradigma (modelo/modo de produção do Direito) liberal-individualista-normativista está esgotado. O crescimento dos direitos transindividuais e a crescente complexidade social (re)clamam novas posturas dos operadores jurídicos (STRECK, 2009, p. 17).

O quadro que se observa é o de uma Sociedade atual altamente complexa e conflituosa, regulada ainda por um Direito e por uma prática jurídica eminentemente individual e positivista, e que carece de uma legislação e de um sistema judicial que resolva de forma eficaz e coletivamente tais demandas.

Registra-se então a necessidade de um repensar o Direito, afim de adequá-lo às transformações e aspirações da Sociedade contemporânea.

Bem o diz Brandão (2001, p. 114-5):

o desenvolvimento tecnológico e eletrônico e o superdimensionamento do Estado iniciados ainda no Estado Moderno, mas que se consolidam e se manifestam mais intensamente no Estado Contemporâneo, terminam por estabelecer uma conflituosidade potencial e abrangente, que vem causar um "desequilíbrio conceitual na própria teoria geral do direito" [...] o desequilíbrio conceitual ocorrente no âmbito da teoria geral do direito, com o afloramento e crescimento dos interesses e direitos difusos e coletivos, não é somente uma modificação nos esquemas conceituais, mas corresponde a uma outra concepção sobre os instrumentos destinados à tutela de tais interesses.

Percebe-se a necessidade de uma legislação e de uma estrutura judiciária próprias para a solução de conflitos transindividuais. A tutela dos direitos difusos, coletivos e individuais homogêneos requer princípios e institutos próprios e adequados às novas realidades sociais e jurídicas.

É mister romper com a tradição individualista da legislação processual civil até então em vigor, e criar um aparato legislativo direcionado para os processos coletivos, com o que, "em sentido político", poder-se-á melhor "determinar em que medida o processo constitui, por si próprio, uma realização das garantias consignadas nos textos constitucionais"5.

Ada Pellegrini Grinover, uma das idealizadoras do anteprojeto do Código Brasileiro de Processos Coletivos percebe a necessidade de um repensar a processualística brasileira, dando-se maior ênfase à tutela das ações coletivas.

Em suas palavras:

a análise dos princípios gerais do direito processual, aplicados aos processos coletivos, demonstrou a feição própria e diversa que eles assumem, autorizando a afirmação de que o processo coletivo adapta os princípios gerais às suas particularidades. Mais vistosa ainda é a diferença entre os institutos fundamentais do processo coletivo em comparação com os do individual.

\footnotetext{
${ }^{5}$ Vide o segundo aspecto de análise do processo proposto por Couture (2008, p. 64).
} 


\section{E arremata:}

Tudo isso autoriza a conclusão a respeito do surgimento e da existência de um novo ramo do direito processual, o direito processual coletivo, contando com princípios revisitados e institutos fundamentais próprios e tendo objeto bemdefinido: a tutela jurisdicional dos interesses ou direitos difusos, coletivos e individuais homogêneos. (GRINOVER, 2007a, p. 15, grifo do autor).

A elaboração de um anteprojeto de Código Brasileiro de Processos Coletivos demonstra o direcionamento da comunidade jurídica brasileira para uma tutela mais eficiente dos conflitos metaindividuais.

A procura por soluções transindividuais das demandas é o elemento de mediação dialética entre fato e norma. $\mathrm{O}$ elemento axiológico proposto por Miguel Reale pode ser percebido na busca por uma nova cultura dentro da processualística brasileira, com a criação de um instrumental próprio para as ações coletivas.

\subsection{A Tutela Coletiva como Ferramenta de Acesso à Justiça}

A tutela coletiva como ferramenta de acesso à Justiça também deve ser analisada como elemento axiológico da elaboração do anteprojeto do Código Brasileiro de Processos Coletivos.

Preliminarmente, extrai-se de Cappelletti um conceito operacional para acesso à justiça, a partir destas reflexões:

a expressão "acesso à Justiça" é reconhecidamente de difícil definição, mas serve para determinar duas finalidades básicas do sistema jurídico - o sistema pelo qual as pessoas podem reivindicar seus direitos e/ou resolver seus litígios sob os auspícios do Estado. Primeiro, o sistema deve ser igualmente acessível a todos; segundo, ele deve produzir resultados que sejam individual e socialmente justos. (CAPPELLETTI; GARTH, 1988, p. 8).

Inicialmente pensado como uma garantia para a defesa dos direitos individuais violados, o direito de ação "foi ampliado, no Brasil, pela Constituição de 1988, à via preventiva, para englobar a ameaça, tendo o novo texto suprimido a referência a direitos individuais.

A redação do inc. XXXV do art. 5ํe é A lei não excluirá da apreciação do Poder Judiciário lesão ou ameaça a direito'.” (CINTRA; GRINOVER; DINAMARCO, 2008, p. 87).

Mas, com o florescimento dos "novos direitos" e o aumento do número de processos coletivos, o acesso à justiça ganhou nova roupagem. A tutela transindividual tem sido encarada como uma nova ferramenta de acesso à justiça, ao garantir às coletividades soluções coletivas de conflitos.

O próprio Cappelletti, ao propor soluções práticas para os problemas de 
acesso à Justiça, considera como primeira onda desse movimento a assistência judiciária para os pobres, nitidamente de caráter individual.

Contudo, a segunda onda do movimento do acesso à Justiça é justamente caracterizada por Cappelletti pela "representação dos interesses difusos", o que demonstra a íntima relação entre tutela coletiva e acesso à Justiça.

Pondera este autor:

o segundo grande movimento no esforço de melhorar o acesso à justiça enfrentou o problema da representação do interesses difusos, assim chamados os interesses coletivos ou grupais, diversos daqueles dos pobres. [...] Centrando seu foco de preocupação especificamente nos interesses difusos, esta segunda onda de reformas forçou a reflexão sobre noções tradicionais muito básicas do processo civil e sobre o papel dos tribunais. [...].

Conclui: "A visão individualista do devido processo judicial está cedendo lugar rapidamente, ou melhor, está se fundindo com uma concepção social, coletiva”. (CAPPELLETTI; GARTH, 1988, p. 49-51).

Cabe ressaltar que no processo coletivo o acesso à Justiça pelo Cidadão tem feições diferentes do que no processo individual. Isso porque no processo coletivo um legitimado atuará em benefício da coletividade. Este "representante adequado" irá promover a defesa do direito desta coletividade, não necessitando que o cidadão busque individualmente a solução de seu conflito.

Assim, o acesso à Justiça nas demandas coletivas pode se dar tanto pelo contato do Cidadão com o seu representante adequado, que militará em seu nome, ou mesmo sem a necessidade deste contato, com o cidadão tendo o seu direito defendido pelo representante independente de provocação deste (Cidadão). A atuação do legitimado pode se dar de forma direta, resguardando o direito de uma coletividade e promovendo diretamente o acesso a Justiça destes cidadãos, sem a necessidade de que estes o provoquem ou ingressem individualmente no Judiciário.

Assinala Grinover: "o acesso à justiça para a tutela de interesses transindividuais, visando a solução de conflitos que, por serem de massa, têm dimensão social e política, assume feição própria e peculiar no processo coletivo.”

E descreve o fenômeno em seu cerne, assim:

O princípio que, no processo individual, diz respeito exclusivamente ao cidadão, objetivando nortear a solução de controvérsias limitadas ao círculo de interesses da pessoa, no processo coletivo transmuda-se em princípio de interesse de uma coletividade, formada por centenas, milhares e às vezes milhões de pessoas. (GRINOVER, 2007a, p. 12).

A visualização da tutela coletiva como forma de concretizar mais completamente o princípio do acesso à justiça, mediante a garantia dos direitos coletivamente 
considerados, inclusive sem a necessidade de provocação do judiciário pelos cidadãos, que terão seus direitos assegurados pela atuação de seus representantes, caracteriza também o elemento axiológico proposto por Reale, para Percepção Jurídica do Anteprojeto do Código Brasileiro de Processos Coletivos.

\section{NORMA}

Consoante Miguel Reale (1994), a norma jurídica "assinala sempre um momento de pausa, de objetividade relativa no decurso das operações incessantemente realizadas pelos indivíduos e pelos grupos, representando a forma positiva de qualificação axiológica do fato em dada conjuntura" (p. 98, grifo do autor).

E mais:

o ordenamento jurídico em vigor corresponde ao "horizonte de estabilidade" alcançado em determinado momento histórico. É por esse motivo que ligo o conceito de norma ao de composição ou de pausa no ritmo tensional que não só relaciona, mas contrapõe fatos a valores, e vice-versa. (REALE, 1994, p. 94, grifo do autor).

Assim, vistos os elementos fáticos e axiológicos relacionados à criação de um instituto próprio para a tutela de direitos coletivos, cabe agora a descrição e o exame do Anteprojeto do Código Brasileiro de Processos Coletivos instrumento jurídico fruto da relação dialética dos fatos e valores atuantes no hodierno momento histórico.

\subsection{O Anteprojeto do Código Brasileiro de Processos Coletivos ${ }^{6}$}

O Anteprojeto do Código Brasileiro de Processos Coletivos, de autoria do Instituto Brasileiro de Processos Coletivos, foi encaminhado ao Ministério da Justiça para análise em janeiro de 2007, após incorporar sugestões da Casa Civil, Secretaria de Assuntos Legislativos, PGFN e dos Ministérios Públicos de Minas Gerais, Paraná, Rio Grande do Sul Paulo.

Composto de seis capítulos e cinqüenta e dois artigos,

o Código Modelo foi profundamente analisado e debatido no Brasil no final de 2003, ao ensejo do encerramento do curso de pós-graduação stricto sensu da Faculdade de Direito da Universidade de São Paulo, por professores e pósgraduandos da disciplina "Processos Coletivos", ministrada em dois semestres por Ada Pellegrini Grinover e Kazuo Watanabe, para verificar como e onde suas normas poderiam ser incorporadas, com vantagem, pela legislação brasileira, sendo a idéia da elaboração de um Código Brasileiro de Processos Coletivos comprometida com o aperfeiçoamento do sistema, sem desfigura-lo. (GRINOVER, 2007b, p. 3).

\footnotetext{
${ }^{6}$ Estamos operando com o texto constante em: http://www.direitoprocessual.org.br/dados/ File/enciclopedia/CBPC\%202007\%2001\%2031\%20-\%20Entregue\%20ao\%20governo.doc a partir do site http://www.direitoprocessual.org.br/, acessado em 07/01/2009.
} 
Concebido para aperfeiçoar a legislação em vigor, com a criação de regras mais abertas e flexíveis, adequadas às demandas coletivas, o Anteprojeto:

pode representar linha de seguimento progressista do direito para uns - aqueles mais apegados à ortodoxia positivista; mas para outros, a resposta adequada aos anseios de efetivação dos direitos de solidariedade, ciclo justo dos novos direitos reconhecidos como os de terceira geração, cujo resultado final redundará na verdadeira efetividade da prestação jurisdicional (SANTOS, 2007, p. 40).

O primeiro capítulo, com 18 artigos, trata das demandas coletivas. Cabe destacar o artigo segundo, que elenca expressamente princípios da tutela jurisdicional coletiva, dentre os quais citamos ${ }^{7}$ : a) acesso à justiça e à ordem jurídica justa; d) tutela coletiva adequada; h) instrumentalidade das formas; j) flexibilização da técnica processual; k) dinâmica do ônus da prova; 1) representatividade adequada; u) aplicação residual do Código de Processo Civil. A partir destes princípios citados (sem exclusão dos outros também elencados no anteprojeto), é possível constatar-se a interação das dimensões fato e valor, que culminaram na elaboração do Anteprojeto em tela.

A dimensão fática pode ser identificada especialmente pelo princípio expresso na alínea “u) aplicação residual do Código de Processo Civil”, que demonstra a necessidade da criação de institutos próprios de Direito Coletivo, ante a inadequação do atual Código de Processo Civil para a tutela dos Direitos Coletivos.

A dimensão axiológica pode ser percebida com maior ênfase nos princípios “a) acesso à justiça e à ordem jurídica justa; d) tutela coletiva adequada; 1) representatividade adequada”. A adoção expressa de tais princípios demonstra a preocupação valorativa na mudança do paradigma processual-individualista, a fim de se proporcionar uma tutela coletiva mais efetiva, com a concretização de direitos difusos, coletivos e individuais homogêneos, e propiciando um acesso à justiça diferenciado e adequado às questões transindividuais.

O capítulo segundo, com dezenove artigos (art. 19 a art. 37) trata da ação coletiva ativa, com disposições gerais acerca da ação coletiva ativa, e com artigos específicos para a tutela de interesses ou direitos individuais homogêneos. É de se ressaltar a preocupação do legislador com a efetividade e a celeridade processual, ao elaborar normas mais abertas e flexíveis. Como exemplo cita-se o art. 24, §4을 do Anteprojeto, cujo teor é:

Art. 24. Da instrução da inicial e do valor da causa.

$\S 4^{\circ} \mathrm{Na}$ hipótese de ser incomensurável ou inestimável o valor dos danos coletivos, fica dispensada a indicação do valor da causa na petição inicial, cabendo ao juiz fixá-lo na sentença. (ANTEPROJETO..., 2007, p. 17-8).

\footnotetext{
${ }^{7}$ A seleção é subjetiva dos autores deste artigo, tendo como referente a importância para a consistência jurídica e técnica do futuro Código.
} 
Esta disposição representa inovação de desapego da norma ao rigoroso formalismo encampado pelo processo civil individual, como se pode ver no art. 282, V, c/c. o art. 258, ambos do CPC. E mais, demonstra-se a disposição legislativa processual coletiva "apta à aplicação de uma interpretação aberta e flexível [...], que estabelece a compatibilização dos mecanismos processuais com a tutela coletiva de direitos e interesses transindividuais" (SANTOS, 2007, p. 40).

O terceiro capítulo com apenas três artigos (do art. 38 ao art. 40) trata da ação coletiva passiva originária. De forma inovadora, este capítulo introduz no ordenamento jurídico brasileiro a ação coletiva passiva,

ou seja, a ação movida não pelo, mas contra o grupo, categoria ou classe de pessoas. [...] A ação coletiva passiva será admitida para a tutela de interesses ou direitos difusos ou coletivos [...], conquanto os efeitos da sentença possam colher individualmente os membros do grupo, categoria ou classe de pessoas. Por isso, o regime da coisa julgada é perfeitamente simétrico ao fixado para as ações coletivas ativas. (GRINOVER, 2007b, p. 6).

O quarto capítulo, também com três artigos (do art. 41 ao art. 43) regula o Mandado de Segurança Coletivo. Ressaltam-se as inovações trazidas quanto à legitimidade ativa do instituto. Consoante reza o art. 42 do Anteprojeto, o Mandado de Segurança Coletivo pode ser impetrado por: I - o Ministério Público; II - Defensoria Pública; III - partido político com representação no Congresso Nacional; IV - entidade sindical, entidade de classe ou associação legalmente constituída e em funcionamento há pelo mentos um ano; em defesa dos interesses de seus membros ou associados, dispensada a autorização assemblear.

Quanto a isto, Zaneti Jr (2007, p. 388) escreve:

outra inovação importante revela-se na assunção de legitimidade ativa para o Ministério Público e para a Defensoria Pública. Sem sombra de dúvida este será um avanço para o desenvolvimento do instituto, aumentando o espectro de sua aplicação prática. Hoje está claro que o sonho constituinte de legitimar apenas os corpos intermediários da sociedade civil para o mandamus coletivo não resultou no amadurecimento destes legitimados. Ao contrário, geralmente são ainda os órgãos públicos, com especial destaque para o Ministério Público, que atuam na tutela coletiva.

O capítulo quinto, composto por apenas dois artigos (art. 44 e art. 45), dispõe acerca das ações populares. Trazendo poucas alterações ao instituto já existente, prevê o art. 44 que "aplicam-se à ação popular constitucional as disposições do Capítulo I deste Código e as da Lei 4.717, de 29 de junho de 1965”, e o art. 45 que também se aplica à ação de improbidade administrativa, as disposições do Capítulo I deste código, bem como a Lei 8.429, de 2 de junho de 1992.

Por fim, o sexto capítulo, formado por seis artigos (do art. 46 ao art. 52), trata das disposições finais. Igualmente neste capítulo é possível se observar 
elementos fáticos e axiológicos que inspiraram a elaboração deste Anteprojeto. $\mathrm{O}$ art. 48, por exemplo, trata dos princípios de interpretação. Diz o artigo: "Este Código será interpretado de forma aberta e flexível, compatível com a tutela dos direitos coletivos".

Percebe-se a preocupação do legislador em demonstrar que o atual Processo Civil se encontra defasado no tocante à tutela coletiva, e que o Processo Coletivo deve ser concebido de forma inovadora, com interpretações abertas e flexíveis, mais adequadas à solução das demandas transindividuais.

\section{CONSIDERAÇÕES FINAIS}

Neste artigo relata-se os resultados de um exercício de utilização da Teoria Tridimensional do Direito formulada por Miguel Reale, como instrumento de Percepção Jurídica para examinar, descrever e emitir objetivos juízos valorativos acerca do Anteprojeto do Código Brasileiro de Processos Coletivos.

Procurou-se caracterizar os elementos fáticos, axiológicos e normativos, bem como temporais e de poder, relacionados à elaboração do referido Anteprojeto, para demonstrar, a partir destas dimensões, a adequação e a necessidade de um ordenamento próprio para tutelar as demandas coletivas.

Percebeu-se que o tensionamento fato-valor relacionado à tutela coletiva, aliado ao atual momento histórico e aos poderes atuantes na Sociedade, resultou em uma proposta de norma jurídica legal que busca a ruptura com o paradigma do processo civil individual, pelo surgimento de princípios e institutos próprios voltados para o processo coletivo.

Assim, conclui-se reconhecendo a importância da criação do novo Código e da aprovação do citado Anteprojeto, de modo que o Brasil possua um Código de Processos Coletivos em consonância com a dinamicidade da vida coletiva que incide sobre a Sociedade, e para que o ordenamento jurídico brasileiro prossiga buscando a sustentação em três fundamentos: "segurança jurídica, justiça e progresso social” (ROUBIER apud REALE, 1994, p. 33).

\section{REFERÊNCIAS}

BOBBIO, Norberto. O problema da guerra e as vias da paz. Tradução de Álvaro Lorencini. São Paulo: Editora UNESP, 2003. Título original: Il problema della guerra e le vie della pace.

BRANDÃO, Paulo de Tarso. Ações Constitucionais: novos direitos e acesso à justiça. Florianópolis: Habitus Editora, 2001.

. Ações Constitucionais: novos direitos e acesso à justiça. 2 ed. rev. amp. Florianópolis: OAB/SC Editora, 2006. 
CAPPELLETTI, Mauro; GARTH, Bryant. Acesso à Justiça. Tradução de Ellen Gracie Northfleet. Porto Alegre: S. Fabris Editora, 1988.

COUTURE, Eduardo J. Fundamentos do Direito Processual Civil. Tradução de Henrique de Carvalho. Florianópolis: Conceito Editorial, 2008.

CINTRA, Antonio Carlos de Araújo; GRINOVER, Ada Pellegrini; DINAMARCO, Cândido Rangel. Teoria Geral do Processo. 24. ed. São Paulo: Malheiros, 2008.

GRINOVER, Ada Pellegrini. Direito Processual Coletivo. In: GRINOVER, Ada Pellegrini; MENDES, Aluísio Gonçalves de Castro; WATANABE, Kazuo (Coord.). Direito Processual Coletivo e o anteprojeto de Código Brasileiro de Processos Coletivos. São Paulo: Editora Revista dos Tribunais, 2007a.

- Exposição de Motivos. In: ANTEPROJETO de Código Brasileiro de Processos Coletivos. São Paulo, 2007b. Disponível em: <http://www. direitoprocessual.org.br/dados/File/enciclopedia/CBPC\%202007\%2001\%20 31\%20-\%20Entregue\%20ao\%20governo.doc>. Acesso em: 7 jan. 2009.

MAZZILI, Hugo Nigro. A defesa dos interesses difusos em juízo: meio ambiente, consumidor, patrimônio cultural, patrimônio público e outros interesses. 18 ed. rev. amp. e atual. São Paulo: Saraiva, 2005.

MEIRELLES, Hely Lopes. Mandado de Segurança. 26. ed. Atualizada por Arnold Wald e Gilmar Ferreira Mendes, com a colaboração de Rodrigo Garcia da Fonseca. São Paulo: Malheiros, 2003.

PASOLD, Cesar Luiz. Metodologia da Pesquisa Jurídica: Teoria e Prática. 11. ed. rev. atual. Florianópolis: Conceito Editorial; Millennium, 2008.

Função Social do Estado Contemporâneo. 3. ed. rev. atual. amp. Florianópolis: OAB/SC Editora, 2003.

Reflexões sobre o Poder e o Direito. 2. ed. Florianópolis: Editora Estudantil, 1988.

REALE, Miguel. Teoria Tridimensional do Direito - situação atual. 5. ed. São Paulo: Saraiva, 1994.

STRECK, Lenio Luiz. Hermenêutica Jurídica e(m) Crise: uma exploração hermenêutica da construção do Direito. 8. ed. ver. atual. Porto Alegre: Livraria do Advogado Editora, 2009. 